Running Header: WRITING FOR SUBMISSION

Writing Manuscripts for Case Studies in Sport and Exercise Psychology

Stewart T. Cotterill

University of Winchester

Robert J. Schinke

Laurentian University

Richard Thelwell

University of Portsmouth 


\section{Writing Manuscripts for Case Studies in Sport and Exercise Psychology}

The mandate for Case Studies in Sport and Exercise Psychology (CSSEP) is to provide contemporary examples of sport and exercise psychology practice from and for a global audience of emerging and established professionals. While there are differing views regarding the specific nature of the case study approach in the social science literature there are a number of specific points that appear to be consistent. Specifically, that the case study should have a 'case' that is the object of study or evaluation; that the case is a complex functioning unit; investigation of the case should take place in the case's natural environment; and should be contemporary (Yin, 2003; Stake, 1998; Miles \& Huberman, 1994). Building on this point Stake (1998) suggested that the crucial focus of a case study is not the methods used, rather that it is defined by an interest in the specific case of interest. The case studies in the CSSEP context are designed to provide the reader with practical examples of localized approaches that bridge theory and situated practice, as a reciprocal process. These "sensitized practices" are meant to extend beyond the delivery of services to practitioner reflexivity, or critical introspection, regarding what worked (and did not work), why, one's culpability, and how to augment understanding and further delivery to clients (Cropley, Hanton, \& Miles, 2010; Schinke, McGannon, Parham, \& Lane, 2012). Concurrently, it is hoped that the case studies in this journal will offer a developmental opportunity for readers to reflect upon the utility of each application in relation to one's own experiences within a backdrop of a local and dynamic performance context. The reader is then meant to benefit from a comprehensive understanding of the approach(es) utilized in each case, situated in relation to the author's formal and practical qualifications. Consequently, authors are required to articulate why they have adopted their particular approach, in keeping with an 
evidence-based approach to practice (Cotterill, Weston, \& Breslin, 2016). What follows are standards, or objectives, that we believe would enrich case study submissions, as well as recommendations regarding the structure and presentation of submissions to CSSEP.

\section{Objective 1: Sharing in a Community of Practice}

A core aim of this journal is to bring together applied practitioners and applied researchers in a way (i.e. through case study approaches) that has not been featured consistently in the academic literature to present despite the importance of contextual understanding (Cotterill, Weston, \& Breslin, 2016). For CSSEP to be successful we need to ensure that the innovative and highly effective practitioners who are fully immersed in the field of applied sport and exercise psychology feel able and willing to share their experiences, successes, and challenges. Only through openness can we create a positive community of practice that drives the field of sport and exercise psychology forward.

\section{Objective 2: Situated Approaches}

Authors of successful submissions in this journal need to demonstrate theoretical rigor and criticality. At the same time CSSEP is designed for practitioners, trainees and applied researchers interested in the uniqueness of local contexts. Hence, an understanding of supporting evidence is paramount to acceptance, though the senior editorial board members are aware that emerging practices exist beyond the confines of mainstream research and practice (e.g., Schinke, Papaioannou, \& Schack, 2016). Novel and creative approaches are thus welcomed, situated in lesser-known scholarship from the global community. CSSEP's editorial board is keen to consider submissions that centralize creative and innovative approaches to practice that might also be ahead of the empirical evidence base, but not devoid of a broader evidence- 
based foundation. All creative solutions emerge from some pre-existing knowledge and it is that foundation that needs to be communicated in these cases.

\section{Objective 3: Situating the Self}

Reflection on the experience is an important aspect of the case studies we seek for publication. Reflection is meant to reveal an openness on the part of authors to willingly engage with one's own practice, situating oneself personally (e.g., gender, culture, sexual orientation, nationality) and professionally (e.g., education, practical experience, theoretical approach(es), favoured applications) in a context (Terry, 2009). Building on one's background, reflection extends to the effectiveness of the intervention(s) within the environment, working with a specific client group (see Gilbourne \& Richardson, 2006). We do not offer a prescribed model of reflection, but there is a need to demonstrate a structured approach to this reflection; at its best, reflection is meant to be thorough, exhaustive, and critically sound (Knowles \& Gilbourne, 2010). This meta-cognitive approach is designed to demonstrate an ability to think about (and evaluate) the things that you think about while working as a practitioner or researcher in the field (e.g., McGannon \& Johnson, 2009).

\section{Structure}

A general structure for the case studies begins with the author(s) reflecting on the context and the key agents involved, with special attention paid to the author(s) themselves, their approach to practice, their philosophy, and a brief outline of the experiences that have helped to shape and evolve their particular approach. Then, after explaining the case in detail, its theoretical underpinning, the focal interventions and outcomes, there will be a strong focus on reflection. Authors will be required to reflect on their experience, the effectiveness of their approach, things they would do differently, and major lessons learned. 


\section{Presentation}

Authors should consult the "Submitting a case to Case Studies in Sport and Exercise Psychology" webpage on the CSSEP pages on the Human Kinetics website when developing presentation and formatting of manuscripts for publication in CSSEP. Authors should also check that the manuscript is prepared in accordance with the rules of APA style presented in the Publication Manual of the American Psychological Association (6th ed., 2010) and at www.apastyle.com. Specifically authors should check the following:

- That identifying information on the title page or in the content of the manuscript is removed or concealed.

- That an accompanying cover letter, in line with APA style is included with the submission.

- That the preponderance of the manuscript content is practically oriented.

- That the manuscript is between 15 and 25 double-spaced pages (4000-6000 words) in length (inclusive of Abstract, tables, figures, and references).

- That the manuscript includes an abstract of between 100-200 words.

- That continuous line numbering is included throughout the manuscript.

- That the writing style is clear and engaging. Authors can achieve this by presenting their ideas in an orderly manner and by expressing them smoothly and precisely. Establishing a tone that conveys the essential points of the work in an interesting manner will engage readers and communicate the ideas more effectively. Esoteric terminology or abbreviations should be avoided.

- That sub-headings are used throughout the manuscript to help organize the content and guide the reader.

The manuscript itself should include the following sections: 
1. Context: A reflection on the context and the key agents underpinning the case study. In particular, focusing on the author(s), their approach to practice, their philosophy and briefly outlining experiences that have helped to shape and evolve their particular approach.

2. The Case: explaining in detail the case itself and the focal interventions (tactics) and outcomes.

3. Reflections: The author(s) will be required to reflect on their experience, their approach, things they would do differently, lessons learnt, and recommendations for future practice, research or both.

All manuscripts should be submitted electronically in Microsoft word format (.dox) to the CSSEP ScholarOne manuscript site mc.manuscriptcentral.com/hk_cssep. 


\section{References}

Cotterill, S. T., Weston, N., \& Breslin, G. (2017). Introduction. In. S. Cotterill, N Weston, \& G Breslin (Eds.) Sport and exercise psychology: Practitioner case studies (pp. 1-6). Oxford: Wiley.

Cropley, B., Hanton, S., \& Miles, A. (2010). Exploring the relationship between reflective and effective practice in applied sport psychology. The Sport Psychologist, 24, 521-541.

Gilbourne, D., \& Richardson, D. (2006). Tales from the field: Personal reflections on the provision of psychological support in professional soccer. Psychology of Sport and Exercise, 7, 325-337. Doi:10.1016/j.psychsport.2005.04.004

Knowles, Z., \& Gilbourne, D. (2010). Aspiration, inspiration, and illustration: Initiating debate on reflective practice writing. The Sport Psychologist, 24, 504520.

McGannon, K. R., \& Johnson, C. R. (2009). Strategies for reflective cultural sport psychology research. In R. J. Schinke \& S. J. Hanrahan (Eds.), Cultural sport psychology (pp. 57-75). Champaign, IL: Human Kinetics.

Miles, M. B., \& Huberman, A. M. (1994). Qualitative Data Analysis. Thousand Oaks: Sage.

Schinke, R. J., McGannon, K. R., Parham, W. D., \& Lane, A. M. (2012). Toward cultural praxis and cultural sensitivity: Strategies for self-reflexive sport psychology practice. Quest, 64, 34-46. Doi:10.1080/00336297.2012.653264

Schinke, R. J., Papaionnou, A. G., \& Schack, T. Sport psychology in emerging countries: An introduction. International Journal of Sport and Exercise Psychology, 14, 103-109. Doi:10.1080/1612197X.2016.1155828

Stake, R. (1998). Case Studies. In N. Denzin \& Y. Lincoln (Eds.), Strategies of 
Qualitative Inquiry. Thousand Oaks, London, New Delhi: Sage.

Terry, P. (2009). Strategies for reflective sport psychology practice. In R. J. Schinke \& S. J. Hanrahan (Eds.), Cultural sport psychology (pp. 79-89). Champaign, IL: Human Kinetics.

Yin, R. K. (2003). Case study research: Design and methods (3rd ed.). Thousand Oaks, CA: Sage. 